\title{
The Importance of Economic Perspective and Quantitative Approaches in Oncology Value Frameworks of Drug Selection and Shared Decision Making
}

\author{
A. Reginald Waldeck, PhD; Marc F. Botteman, MSc, MA; \\ Richard E. White, MA, PhD; and Ben A. van Hout, PhD
}

\section{SUMMARY}

The debate around value in oncology drug selection has been prominent in recent years, and several professional bodies have furthered this debate by advocating for so-called value frameworks. Herein, we provide a viewpoint on these value frameworks, emphasizing the need to consider 4 key aspects: (1) the economic underpinnings of value; (2) the importance of the perspective adopted in the valuation; (3) the importance of the difference between absolute and relative measures of risk and measuring patient preferences; and (4) the recognition of multiple quality-of-life $(\mathrm{Q} \mathrm{L})$ domains, and the aggregation and valuation of those domains, through utilities within a multicriteria decision analysis, may allow prioritization of QoL above the tallying of safety events, particularly in a value framework focusing on the individual patient.

While several frameworks exist, they incorporate different attributes and-importantly-assess value from alternative perspectives, including those of patients, regulators, payers, and society. The various perspectives necessarily lead to potentially different, if not sometimes divergent, conclusions about the valuation. We show that the perspective of the valuation affects the framing of the risk/benefit question and the methodology to measure the individual patient choice, or preference, as opposed to the collective, or population, choice.

We focus specifically on the American Society of Clinical Oncology (ASCO) Value Framework. We argue that its laudable intent to assist in shared clinician-patient decision making can be augmented by more formally adopting methodology underpinned by micro- and health economic concepts, as well as application of formal quantitative approaches. Our recommendations for value frameworks focusing on the individual patient, such as the ASCO Value Framework, are 3-fold: (1) ensure that stakeholders understand the importance of the adopted (economic) perspective; (2) consider using exclusively absolute measures of risk and formal patientpreference methodology; and (3) consider foregoing safety parameters for higher-order utility considerations.

J Manag Care Spec Pharm. 2017;23(6-a):S6-S12

Copyright $\odot 2017$, Academy of Managed Care Pharmacy. All rights reserved.
T he debate around value in health care, and specifically in oncology drug selection, has been highly prominent in recent years. ${ }^{1-5} \mathrm{~A}$ number of professional bodies (including the Memorial Sloan Kettering Cancer Center, the American Society of Clinical Oncology [ASCO], the National Comprehensive Cancer Network, the Institute for Clinical and Economic Review, and the European Society of Medical Oncology [ESMO]) have furthered this debate by introducing so-called value frameworks., ${ }^{1,26-10}$ Each value framework captures similar, as well as different, aspects of clinical and economic value and cost. These value frameworks have been well described ${ }^{1,2,6,7,11,12}$ and critiqued ${ }^{2,10,13-33}$ to highlight potential areas for improvement. In this article, we focus on the ASCO Value Framework, since it is based in the United States and specifically intended to address the interaction between health care provider (HCP) and individual patient. We address the following 4 aspects by applying microeconomic concepts, while recognizing that behavioral economics may provide additional thinking ${ }^{34}$ : (1) reintroduce the debate around the concept of value in more formalized microeconomic terms; (2) clarify the importance of the economic perspective adopted in the valuation; (3) critically appraise the use of certain statistical measures in the context of the patient-HCP interaction, specifically the difference between relative and absolute measures of risk, as well as using formal patient-preference methodology; and (4) provide rationale supporting the foregoing of safety parameters for higher-order utilities.

\section{Definitions of Value}

The term "value" in health care is used abundantly, yet a single definition does not appear to exist nor is likely to emerge. The main reason for this lack of definition can be found in a phrase from economist Joan Robinson about the related concept of utility. She writes: "Utility is a metaphysical concept of impregnable circularity; utility is the quality in commodities that makes individuals want to buy them, and the fact that individuals want to buy commodities shows that they have utility." ${ }^{35}$ Ultimately, the value of a commodity depends on one's willingness to trade for something else that has value. This may be the remote risk of a serious side effect for the possibility of additional years of life or anything else that has value. 
Thus, when following this idea, one might question whether it is correct to define value, as suggested by Porter (2010), to contain a numerator and a denominator, with outcome being the numerator and costs being the denominator ${ }^{36}$ :

\section{Value $=$ Outcome $\div$ Cost}

Nevertheless, in the U.S. third-party payer context, Equation 1 may be viewed as a generally accepted way of expressing value. Equation 1 may also be viewed as a cost-consequence analysis ${ }^{37}$ in which outcomes and costs are tallied, yet not aggregated, into a single measure. Equation 1 expresses the ratio of an intervention's outputs for its cost; for example, the intervention produces, on average, 21 months of survival for a given cost of, say, $\$ 100,000$. Therefore, the value according to Equation 1 is 1.75 (life-years) $\div \$ 100,000$, or expressed in words: "Providing 1.75 years of life for a cost of $\$ 100,000$."

For the advanced disease setting, the outcome measures in the updated version of the ASCO Value Framework ${ }^{31}$ include the hazard ratio (HR) for overall survival (OS) or progression-free survival (PFS), median OS or PFS or response rate (RR), toxicity, an assessment of the tail of the survival curve, palliation, QoL, and the absence or presence of a treatment-free interval. For the adjuvant setting, the outcome measures include the HR for OS or disease-free survival (DFS), median OS or DFS, toxicity, and the tail of the curve. The ASCO Value Framework may be viewed as a cost-consequence analysis in which an actual score for the consequences is tallied up and juxtaposed against the wholesale acquisition cost and/or the patient copay. ${ }^{38}$ Hence, the ASCO framework is a major step forward from Equation 1, since it aims to quantify good value.

Another measure, introduced over 40 years ago and used in formal economic evaluation, or cost-effectiveness analysis (CEA) of health care interventions, is called the incremental cost-effectiveness ratio (ICER). ${ }^{39}$ This measure is a key criterion of the value framework of the Institute for Clinical and Economic Review. ${ }^{6}$

\section{Incremental Cost-Effectiveness Ratio $=\frac{\operatorname{Cost}(A)-\operatorname{Cost}(B)}{\operatorname{Outcome}(A)-\operatorname{Outcome}(B)}$}

Cost encompasses all direct medical costs and outcomes in a CEA. In oncology, the outcome measure is usually OS or quality-adjusted survival, when available, resulting in a costutility analysis. In the latter, the denominator is the difference in quality-adjusted life-years (QALYs). ${ }^{39}$ Equation 2 may be characterized by a numerator of, for example, 21-15 months of incremental survival, assuming that the comparator agent provides 15 months of survival, and a cost difference of $\$ 100,000$ $\$ 50,000$, assuming that the comparator cost is $\$ 50,000$; hence, the ICER is $\$ 50,000$ per 0.5 life-years gained, or $\$ 100,000$ per life-year gained. Moreover, thresholds in terms of cost per QALY for what may be considered good value for money are set by certain non-U.S. national payer agencies that use Equation 2 for reimbursement decisions, as well as the Institute for Clinical and Economic Review in the United States.

Equation 2 expresses the ratio of inputs and outputs at the margin through a marginal or incremental analysis, calculating the difference in cost and outcome of the intervention, compared with its next best alternative. Marginal analysis is a fundamental tenet of health economics and provides an absolute (i.e., difference) measure of value. ${ }^{39}$ This difference between relative and absolute measures of risk is a key point in expressing value and is closely related to the perspective we take in answering the question "Value to whom?" In addition, using the ratio in a marginal analysis explicitly introduces the trading, and, hence, "valuing" of additional life (outcome) for additional money (cost).

\section{Perspective of the Valuation}

When answering the question "Value to whom?" one quickly gets into formal issues of economic perspective. Many people would argue that this should be the individual patient's perspective; however, there are many different types of patients, as well as collective groups of stakeholders with varying objectives, standing up for different parts of society. For example, specialist societies on behalf of their patient base or budget-holders on behalf of all patients to be treated within their budgets.

In Table 1, we summarize the various perspectives of key stakeholders that are either explicitly mentioned or implicitly addressed in the various value frameworks and include the types of questions that these different stakeholders may ask. Table 1 illustrates the need to be precise about how the attributes addressing these questions would have to be communicated. It becomes apparent that, while some of the questions that different stakeholders might ask require the same measures of benefit (i.e., risk reduction), many questions invoke the need for different concepts.

In the next section of this article, we focus on the individual patient's perspective, as opposed to the population viewpoint that regulators and payers need to take. Table 1 highlights that, unlike other stakeholders, individual patients as consumers of health care are more likely to ask questions in terms of chance and generally ask questions in absolute terms, such as: "How long (requires an absolute measure) may I expect (invokes probability) to live with this condition?" This type of questioning has important implications for the measures of benefit that can be used to answer such questions, while also considering probability-based answers.

To illustrate the individual patient perspective further, we outline potential relevant risk reduction measures and paraphrase the ways these measures would have to be articulated in an HCP-patient interaction. Table 1 attempts to explain the 


\begin{tabular}{|c|c|c|c|}
\hline Stakeholder & Perspective & Wants to Understand & $\begin{array}{l}\text { Relevant Measures and Concepts of Benefit (Risk } \\
\text { Reduction) }\end{array}$ \\
\hline \multirow[t]{7}{*}{ Patient } & \multirow{7}{*}{$\begin{array}{l}\text { Consumer of } \\
\text { health care } \\
\text { intervention }\end{array}$} & What happens if I take the drug? What happens if I don't? & $\begin{array}{l}\text { Invokes probability and independent predictors of survival } \\
\text { (if known) }\end{array}$ \\
\hline & & What are my chances of the drug working? & Invokes probability and risk factors \\
\hline & & How (much) long(er) will I live? & $\begin{array}{l}\text { Invokes probability, mean survival, median survival, and the } \\
\text { shape of the survival curve }\end{array}$ \\
\hline & & $\begin{array}{l}\text { What is my chance of living another year? } \\
\text { What is my chance to be a "long-term" survivor? }\end{array}$ & $\begin{array}{l}\text { Invokes the shape of the survival curve and potentially } \\
\text { certain trade-off decisions }\end{array}$ \\
\hline & & $\begin{array}{l}\text { Will I be able to function and do the things I used to? } \\
\text { Will I be able to continue on "as normal," or not? }\end{array}$ & $\begin{array}{l}\text { Invokes quality measures of survival and their measurement } \\
\text { and uncertainty }\end{array}$ \\
\hline & & Is this drug safe for me to take?51 & Invokes probability and absolute rates (\%) of AEs, SAEs, NNH \\
\hline & & How much will this cost? & $\begin{array}{l}\text { Invokes cost measures, such as copay amounts, deductibles, } \\
\text { and potentially lifetime caps }\end{array}$ \\
\hline \multirow[t]{3}{*}{$\begin{array}{l}\text { Health care } \\
\text { provider }\end{array}$} & \multirow[t]{3}{*}{$\begin{array}{l}\text { Provider of } \\
\text { health care } \\
\text { intervention }\end{array}$} & $\begin{array}{l}\text { Do I have a reasonable expectation that the intervention will } \\
\text { work in my patient? }\end{array}$ & $\begin{array}{l}\text { May be a mix of relative and absolute measures of effect. } \\
\text { Invokes probabilities and (if data exists) potential (patient- } \\
\text { individualized) risk-stratification }\end{array}$ \\
\hline & & How can I minimize/avoid causing harm? & $\begin{array}{l}\text { Absolute rates (\%) of AEs, SAEs and an assessment of the } \\
\text { "risk/benefit" profile }\end{array}$ \\
\hline & & How can I improve the overall well-being of the patient? & Invokes QoL considerations and psychosocial domains \\
\hline \multirow[t]{3}{*}{ Regulator } & \multirow{3}{*}{$\begin{array}{l}\text { Assessor of } \\
\text { "risk/benefit } \\
\text { ratio" (safety } \\
\text { and efficacy) }\end{array}$} & \multicolumn{2}{|c|}{ Is the clinical effect proven and do the efficacy outcomes outweigh the adverse effect profile? Specifically: } \\
\hline & & $\begin{array}{l}\text { (a) Did the study meet its primary endpoint, secondary } \\
\text { endpoints (if a hierarchical test was employed)? }\end{array}$ & $\begin{array}{l}\text { Key measure of effect is the HR } \\
\text { Additional measure is (incremental) median survival } \\
\text { Other measures can relate to (statistics of) secondary } \\
\text { endpoint(s) }\end{array}$ \\
\hline & & $\begin{array}{l}\text { (b) Do we believe the drug's adverse effect profile to be } \\
\text { acceptable, given the remaining level of medical unmet } \\
\text { need in this disease state? }\end{array}$ & $\begin{array}{l}\text { Absolute rates (\%) of AEs, SAEs and an assessment of the } \\
\text { "risk/benefit" profile }\end{array}$ \\
\hline \multirow[t]{8}{*}{ Payer } & \multirow{8}{*}{$\begin{array}{l}\text { Health care } \\
\text { system }\end{array}$} & \multicolumn{2}{|l|}{ Similar questions as the regulator AND } \\
\hline & & $\begin{array}{l}\text { Does the trial population address the population I am } \\
\text { covering? }\end{array}$ & $\begin{array}{l}\text { Requires RWD and potentially additional modeling } \\
\text { approaches }\end{array}$ \\
\hline & & How many patients need treatment to avoid 1 event? & Invokes ARR and NNT (1/ARR) \\
\hline & & Is the comparator drug relevant? & $\begin{array}{l}\text { Relates to the standard of care and "next best alternative" for } \\
\text { marginal analysis in health economics }\end{array}$ \\
\hline & & What cost offsets did the drug show, if any? & Requires a cost-consequence analysis \\
\hline & & $\begin{array}{l}\text { What is the price? } \\
\text { What is the anticipated volume of patients and what is the } \\
\text { impact on my budget? }\end{array}$ & Requires financial modeling \\
\hline & & Does it provide value-for-money? & Requires Equation 1 or 2 \\
\hline & & Is it cost-effective? & Requires Equation 2 \\
\hline Society & $\begin{array}{l}\text { Society as a } \\
\text { whole }\end{array}$ & $\begin{array}{l}\text { Is there ancillary value to society outside of "direct medical } \\
\text { costs," by way of "indirect costs," such as reduced absenteeism, } \\
\text { presenteeism, and avoiding loss of work productivity? }\end{array}$ & $\begin{array}{l}\text { Requires indirect costing methodology, time and motion } \\
\text { studies, and patient-preference methodology }\end{array}$ \\
\hline
\end{tabular}

Note: Mean survival can be readily shown to be equivalent to the area under the survival curve; hence, incremental mean survival can be shown to be equivalent to additional months/years of life gained. ${ }^{52}$

$A E=$ adverse event; $A R R=$ absolute risk reduction; $H R=$ hazard ratio; $N N H=$ number needed to harm; $N N T=$ number needed to treat; $Q \mathrm{oL}=$ quality of life;

$R W D=$ real-world data; $S A E=$ serious adverse event .

measure of benefit in readily understood terms, while holding true, as much as possible, to their formal statistical definitions. Finally, oncology can also take a page from extensive risk prediction work in the cardiovascular space, with equations such as the Framingham risk equations, where simple online risk calculators allow one to estimate a patient's absolute 10-year risk of death based on a set of validated risk factors or covariates. ${ }^{40}$

\section{Measures of Risk and Their Relevance} to the Individual Patient

In Table 2, we use definitions of various measures of relative and absolute risk as they would need to be explained to a patient in an HCP-patient interaction. Table 2 helps clarify why absolute measures of risk are generally better ways to assist a patient, as a health care consumer, in shared 


\begin{tabular}{|c|c|c|c|c|}
\hline Stakeholder/Perspective & Wants to Understand & $\begin{array}{c}\text { What Measure of Risk } \\
\text { Reduction Can Address } \\
\text { the Question? }\end{array}$ & $\begin{array}{l}\text { Measure in Value } \\
\text { Framework?a }\end{array}$ & $\begin{array}{l}\text { How Might the Answer be Articulated } \\
\text { Within the HCP-Patient Interaction }\end{array}$ \\
\hline \multirow[t]{6}{*}{$\begin{array}{l}\text { Patient/consumer of } \\
\text { health care intervention }\end{array}$} & \multirow[t]{3}{*}{$\begin{array}{l}\text { How (much) long(er) } \\
\text { will I live? }\end{array}$} & $\begin{array}{l}\text { Using incremental } \\
\text { median survival }\end{array}$ & $\mathrm{ASCO}, \mathrm{ESMO}$ & $\begin{array}{l}\text { "Fifty percent of the population studied } \\
\text { in the trial of this drug survived for } 16 \\
\text { months. This was } 4 \text { months longer than } \\
\text { for the drug with which it was compared." }\end{array}$ \\
\hline & & Using the HR & ASCO, ESMO & $\begin{array}{l}\text { Strict definition: The treatment in question } \\
\text { will cause the patient to reach death more } \\
\text { slowly (delay death) compared with the } \\
\text { alternative; a treated patient that has not } \\
\text { yet died by a certain time has a chance of } \\
\text { dying at the next (measured) time point, } \\
\text { defined by the HR (i.e., if HR= } 0.5 \text { then } \\
\text { chance }=50 \% \text { ). } \\
\text { Loose definition } \text { b: The reduction in risk rel- } \\
\text { ative to the agent this drug was compared } \\
\text { with was } 50 \% \text { (if HR }=0.50 \text {; l-HR }=50 \% \text { ). }\end{array}$ \\
\hline & & $\begin{array}{l}\text { Using incremental mean } \\
\text { survival = life-years gained }\end{array}$ & MSKCC & $\begin{array}{l}\text { "The average patient in the trial survived } \\
\text { for } 19 \text { months. This was } 4 \text { months lon- } \\
\text { ger than for the drug with which it was } \\
\text { compared." }\end{array}$ \\
\hline & \multirow[t]{2}{*}{$\begin{array}{l}\text { What is my individual } \\
\text { chance of being one of } \\
\text { those long-term } \\
\text { survivors? }\end{array}$} & $\begin{array}{l}\text { Using probability of } \\
\text { survival }\end{array}$ & $\begin{array}{l}\text { Not captured explicitly } \\
\text { in any framework. ASCO } \\
\text { mentions "landmark" (\%) } \\
\text { survival at survival times } \\
\text { relevant to the tail of an } \\
\text { immuno-oncology survival } \\
\text { curve }\end{array}$ & $\begin{array}{l}\text { "There appear to be about } 20 \% \text { of patients } \\
\text { that survive beyond } 3 \text { years."c }\end{array}$ \\
\hline & & $\begin{array}{l}\text { Using the shape of an } \\
\text { immuno-oncology survival } \\
\text { curve (as opposed to that } \\
\text { of chemotherapy)d }\end{array}$ & $\begin{array}{l}\text { ASCO updated framework } \\
\text { has bonus points for the } \\
\text { tail; none include patient } \\
\text { preference }\end{array}$ & $\begin{array}{l}\text { "Using this immuno-oncology agent, } \\
\text { there are/appear to be some patients who } \\
\text { survive (more) long-term...the science to } \\
\text { predict your individual chance needs to } \\
\text { evolve to be able to answer your question } \\
\text { for you specifically."c,d }\end{array}$ \\
\hline & $\begin{array}{l}\text { Will I be able to con- } \\
\text { tinue on "as normal," } \\
\text { or not? }\end{array}$ & $\begin{array}{l}\text { A measure that can be } \\
\text { used is the Trial Outcome } \\
\text { Index, which assesses QoL } \\
\text { and functional well-being }\end{array}$ & $\begin{array}{l}\text { QoL is acknowledged in } \\
\text { ASCO, ESMO, and ICER } \\
\text { value frameworks }\end{array}$ & $\begin{array}{l}\text { "There were some meaningful improve- } \\
\text { ments observed in QoL and functional } \\
\text { well-being of the patients that were } \\
\text { studied." }\end{array}$ \\
\hline
\end{tabular}

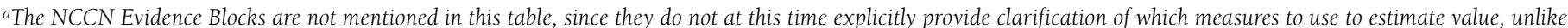
the ASCO, ESMO, MSKCC, and ICER frameworks.

bThis definition is often reported in the medical literature. ${ }^{41}$

cFor simplicity, we assume that there are no known risk factors for the condition or indications to predict long-term survivors.

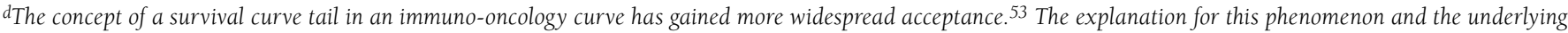

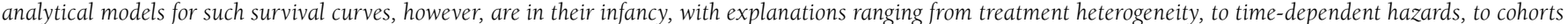

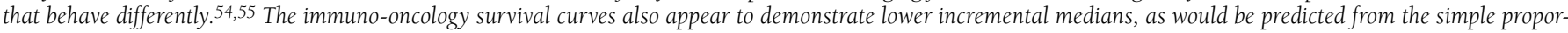
tional hazards assumption.

ASCO=American Society of Clinical Oncology; ESMO = European Society for Medical Oncology; HCP=health care provider; HR=hazard ratio; ICER=Institute for Clinical and Economic Review; MSKCC = Memorial Sloan Kettering Cancer Center; NCCN= National Comprehensive Cancer Network; QoL= quality of life.

decision making, compared with relative measures, since they more directly provide answers to questions of most interest to patients. ${ }^{41}$ It is also noted that the standard, relative measures of risk used in regulatory evaluations, in particular, fall short in addressing the types of questions that patients likely have regarding a therapeutic immuno-oncologic intervention. The regulatory perspective is included in Table 1 to underscore the context for relative measures of risk required for regulatory evaluation, which often shape the HCP perspective and vernacular of communicating risk, as reflected by the ASCO Value Framework. In addition, Table 2 clarifies that probability and preference-based concepts can further facilitate capture of the individual patient perspective. ${ }^{42}$

The exercise of articulating the measures used in the value frameworks, with the patient as the audience, clarifies the following: Relative measures of risk reduction, such as relative risks, odds ratios, and hazard ratios (HR), are difficult to articulate correctly and intuitively to a layperson. In 
addition, literature supports the use of absolute measures of risk in oncology patient communication, since unlike relative risks, they do not tend to overestimate the magnitude of the benefit as perceived by the patient. ${ }^{41,43-45}$

In addition, such measures, while particularly valuable from a regulator's perspective, are much less so from an individual patient perspective. Absolute measures of risk reduction, such as additional months of survival, are more intuitive to the patient and therefore can be considered more "patient-relevant." The revision of the ASCO Value Framework also acknowledges some of these issues: "To avoid the misinterpretation that a favorable HR necessarily represents a large absolute gain in OS or PFS, it is incumbent upon the physician, at the point of care, to explain the absolute difference in survival (e.g., on average, a patient can expect an improvement of $\mathrm{x}$ weeks or months) with the test regimen when compared with the standard of care. It is essential to understand that the framework is meant to be modified at the point of care, as a physician and patient finalize a regimen." ${ }^{31}$ The ESMO Value Framework has recognized this also and reports on the relationship between the HR and incremental months of OS, scrutinizing for face validity, coherence, and consistency. ${ }^{7}$

It is important to note that with an individual patient in mind, the individual's likelihood of an event also needs to be considered. Even a concept such as mean, or average, survival, ${ }^{31}$ while arguably more accurate from a patient's standpoint than median survival, does not account for the individual patient perspective. Note that use of the word "average" in the ASCO Value Framework is incorrect. "Average" equates to the restricted mean survival, which is mathematically equivalent to the area under the curve in the absence of censoring. Mean survival is by definition greater than median survival for survival-time distributions, which are typically right-skewed; this point is particularly relevant for immuno-oncology survival curves demonstrating the now well-known tail (i.e., displaying nonproportional hazards behavior). ${ }^{46-48}$

However, mean survival also does not allow for the patient's preference to be accounted for in a meaningful way. For instance, it has been shown that a majority of cancer patients prefer a "hopeful gamble" (i.e., providing a lower possibility of longer-term survival, such as might be afforded by the tail of an immuno-oncologic) over a "safe bet" offering a certain median survival and thus may be willing to accept a risk of greater short-term mortality in exchange for a lower chance at a large, more meaningful gain in survival. ${ }^{47}$ The updated ASCO Value Framework does recognize the value of the tail in immuno-oncology and has incorporated this into its updated framework, ${ }^{31}$ but it does not yet go as far as considering patient preference related to the possibility of being part of that tail.

\section{Multicriteria Decision Analysis, 0oL, and Utility}

One might argue that all value frameworks may be viewed as simple, practical forms of multicriteria (attribute) decision (utility) analysis. Utility is a way of valuing QoL and represents an individual's relative satisfaction with a health state, on a scale from 0 (representing death) to 1 (representing perfect health). ${ }^{42}$ The European Organization for Research and Treatment of Cancer Quality of Life Questionnaire Core 30 (EORTC QLQ-C30) is an instrument frequently used to measure quality of life in cancer patients. ${ }^{48}$ The EQ-5D is a welldescribed utility instrument aimed at valuing general health through domains of mobility, self-care, usual activities, pain/ discomfort and anxiety/depression. ${ }^{16,49}$ Efforts to map the relationship between the EORTC QLQ-C30 and EQ-5D-based utility values at the individual patient level have been performed. ${ }^{48}$ This field continues to evolve and is worth tracking closely to gain further insight into how individual patients value various QoL domains.

These QoL considerations may supersede individual side effects, since their implications tend to "ladder up" to more overarching QoL considerations. This therefore raises the question of whether in a value framework intended for the individual patient, the safety of a compound can be left out altogether as long as an acceptable form of capture of patient-relevant QoL is included and valued in a utility score. ${ }^{50}$

\section{Discussion}

The concept of value in oncology has gained tremendous traction over the last few years. While there exist various definitions of value, some qualitative (e.g., Equation 1) and some quantitative (e.g., Equation 2), perhaps the most important aspect in this debate is to be thoughtful about what definition of value may be most appropriate, given the perspective of the audience (see Table 1). We have focused on the ASCO Value Framework and its laudable intent to attempt to clarify elements of value that can be communicated within the HCP-patient interaction. We performed a mental exercise of articulating various measures of risk and critically appraised their relevance from the individual patient's perspective. We argue that by adopting the individual patient perspective, the components for further improvement of the existing value frameworks, notably by ASCO, become more self-evident.

\section{Recommendations}

Our recommendations are that a value framework focused on the individual HCP-patient interaction can benefit from 3 straightforward, yet important further improvements: (1) use exclusively absolute measures of risk; (2) augment the framework through recognizing that valuation of outcomes by the individual patient has a probabilistic element to it and apply established patient-preference methodology to capture value trade-offs (e.g., per the previously mentioned hopeful gambles 
vs. safe bets); and (3) consider losing safety and tolerability parameters for more multidomain, patient-relevant QoL considerations and incorporate evolving progress in this area. We believe that through addressing these aspects, coupled with a cross-functional dialogue of relevant stakeholders, further progress can be made towards a value framework that is even more meaningful to the individual patient.

\section{Authors}

A. REGINALD WALDECK, PhD, and RICHARD E. WHITE, MA, $P h D$, Celldex Therapeutics, Hampton, New Jersey, USA. MARC F. BOTTEMAN, MSc, MA, Pharmerit International, Bethesda, Maryland, USA, and BEN A. VAN HOUT, PhD, Pharmerit International, York, United Kingdom.

AUTHOR CORRESPONDENCE: A. Reginald Waldeck, PhD, Vice President Market Access, Pricing \& Health Economics, Celldex Therapeutics, 53 Frontage Rd., Ste. 220, Hampton, New Jersey 08827. Tel.: 908.200.7550; E-mail: rwaldeck@celldex.com.

\section{DISCLOSURES}

No funding was received for conceptualizing, writing, and/or editing this manuscript. Waldeck and White are employees of, and received stock option grants from, Celldex Therapeutics. Van Hout and Botteman are employees and shareholders of Pharmerit International. Pharmerit International is a research contractor for Celldex. All authors have retained editorial control of the content of the manuscript.

Conceptualization of this viewpoint article was contributed primarily by Waldeck, along with Botteman, White, and van Hout. Data analysis and revision of the manuscript was contributed equally by all the authors. The manuscript was written by Waldeck, Botteman, van Hout, and White.

\section{ACKNOWLEDGMENTS}

The authors acknowledge Namita Joshi, PhD, Katie Farrey, and Sarah Ronnebaum, PhD, for their assistance with editorial support and referencing.

\section{REFERENCES}

1. Rémuzat C, Chouaid C, Auquier P, Kornfeld A, Toumi M. Comparison of the European Society for Medical Oncology Magnitude of Clinical Benefit Scale (Esmo-MCBS) and the American Society of Clinical Oncology (Asco) Framework for Assessing Value in Cancer Care. Value Health. 2016;19(7):A357 [Abstract PRM1]

2. Schnipper L, Davidson N, Wollins D, et al. American Society of Clinical Oncology statement: a conceptual framework to assess the value of cancer treatment options. J Clin Oncol. 2015;33(23):2563-77.

3. Ojerholm E, Halpern S, Bekelman J. Default options: opportunities to improve quality and value in oncology. J Clin Oncol. 2016;34(16):1844-47.

4. Cheung M, Sabharwal M, Chambers A, Han D, Sabarre K, Chan K. Multiple dimensions of value: evaluative frameworks for new cancer therapies. J Clin Oncol. 2016;34(12):1428-29.

5. Goldstein D. Understanding the value of cancer drugs-the devil is in the detail. Cancer. 2016;122(15):2292-95.
6. Institue for Clinical and Economic Review. ICER value assessment framework: 1.0 to 2.0. ICER webinar. July 29, 2016. Available at: http:// icer-review.org/wp-content/uploads/2016/02/Value-Assessment-Frameworkslides-for-July-29-webinar-FINAL.pdf. Accessed April 10, 2017.

7. Angelis A, Kanavos P. Application of a value framework based on multiple criteria decision analysis in the context of health technology assessment: a series of case studies with decision makers across European countries. Value Health. 2016;19(7):A360 [Abstract PRM17].

8. Yeung K, Basu A, Hansen R, Watkins J, Sullivan S. Impact of a valuebased formulary on medication utilization, health services utilization, and expenditures. Med Care. 2017;55(2):191-98.

9. Carlson R, Jonasch E. NCCN Evidence Blocks. J Natl Compr Canc Netw. 2016;14(5S):616-19

10. Cherny N, Sullivan R, Dafni U, et al. A standardised, generic, validated approach to stratify the magnitude of clinical benefit that can be anticipated from anti-cancer therapies: the European Society for Medical Oncology Magnitude of Clinical Benefit Scale (ESMO-MCBS). Ann Oncol. 2015;26(8):1547-73

11. Bach P. A new way to define value in drug pricing. NEJM Catalyst. February 24, 2016. Available at: http://catalyst.nejm.org/a-new-way-todefine-value-in-drug-pricing./. Accessed April 10, 2017.

12. Maervoet J, Moise P, Naidoo S. Overview and comparison of frameworks for the valuation of oncology drugs. Value Health. 2016;19(3):Al68 [Abstract PCN194].

13. Memorial Sloan Kettering Cancer Center. DrugAbacus methods. 2016. Available at: http://www.drugabacus.org/methods/. Accessed April 10, 2017.

14. Butcher L. Where ASCO's new cancer care value plan falls short. Oncology Times. 2015;37(19):1, 10-13. Available at: http://journals.lww.com/ oncology-times/Fulltext/2015/10100/Where_ASCO_s_New_Cancer_Care_ Value_Plan_Falls.1.aspx. Accessed April 10, 2017.

15. Subramanian R, Schorr K. How valuable is a cancer therapy? It depends on who you ask. Value Health. 2016;19(3):A221 [Abstract PHP195]. Available at: http://www.valueinhealthjournal.com/article/S1098-3015(16)00900-1/ abstract. Accessed April 27, 2017.

16. Burkholder R. Value at the crossroads, part II. The Catalyst. September 8, 2015. Available at: http://catalyst.phrma.org/value-at-the-crossroads-part-ii. Accessed April 10, 2017.

17. Kelly C. Oncology drug value tools from NCCN, ASCO to get realworld testing. Pink Sheet. December 3, 2015. Available at: https://pink. pharmamedtechbi.com/PS078111/Oncology-Drug-Value-Tools-From-NCCNASCO-To-Get-RealWorld-Testing. Accessed April 10, 2017.

18. Lindgren P, Jönsson B, Wilking N. Assessing the Esmo magnitude of clinical benefit scale from a health economics perspective. Value Health. 2015;18(7):A569 [Abstract PHP317]. Available at: http://www.valueinhealthjournal.com/article/S1098-3015(15)03948-0/abstract. Accessed April 10, 2017.

19. Dubois R. NPC comments on ICER value assessment framework. Letter. National Pharmaceutical Council. October 13, 2015. Available at: http:// www.npcnow.org/commentary/npc-comments-icer-value-assessmentframework. Accessed April 10, 2017.

20. Young R. Value-based cancer care. N Engl J Med. 2015;373(27):2593-95.

21. Neumann P, Cohen J. Measuring the value of prescription drugs. N Engl J Med. 2015;373(27):2595-97.

22. Schoonveld E. Oncology drug pricing after ASCO value framework and DrugAbacus. ZS Associates. July 21, 2015. Available at: http://info.zs.com/ priceofglobalhealth/oncology-drug-pricing-after-acso-value-framework-anddrugabacus?hsFormKey=47f0b9dlf6077155208360fc2dl45c4b. Accessed April 10, 2017.

23. Sullivan D. AstraZeneca commentary on oncology value tools. Value-Based Cancer Care Perspectives. Vol. 6, no 9. October 2015. Available at: http:// www.valuebasedcancer.com/issue-archive/2015/october-2015-vol-6-no-9/ astrazeneca-commentary-on-oncology-value-tools/. Accessed April 10, 2017. 
24. Senior M. Scoring value: new tools challenge pharma's U.S. pricing bonanza. In vivo: the Business \& Medicine Report. October 2015.

Available at: http://www.realendpoints.com/wp-content/uploads/2015/10/ ValueDrugs_IV15103.pdf. Accessed April 10, 2017.

25. Li J, Asabere A, Kelly S. Application of ASCO value framework evaluations of net health benefit for oncology drugs launched in the United States between 2013 and 2015. Value Health. 2015;18(7):A489 [Abstract PCN333].

26. Scher H, Fizazi K, Saad F, et al. Increased survival with enzalutamide in prostate cancer after chemotherapy. N Engl J Med. 2012;367(13):1187-97.

27. Howard D, Bach P, Berndt E, Conti R. Pricing in the market for anticancer drugs. J Econ Perspect. 2015;29(1):139-62.

28. Todd L. Letter to Steven D. Pierson re Institute for Clinical and Economic Review (ICER) value framework. October 9, 2015. Available at: https://www.bio.org/sites/default/files/BIO\%20Final\%20Comments_ ICER\%20Value\%20Framework_9\%20October\%202015.pdf. Accessed April 10, 2017.

29. Angelis A, Kanavos P. Critique of the American Society of Clinical Oncology value assessment framework for cancer treatments: putting methodologic robustness first. J Clin Oncol. 2016;34(24):2935-36.

30. Weber J, Drakeman D. Comment on the American Society of Clinical Oncology value statement. J Clin Oncol. 2016;34(24):2937-38.

31. Schnipper L, Davidson N, Wollins D, et al. Updating the American Society of Clinical Oncology value framework: revisions and reflections in response to comments received. J Clin Oncol. 2016;34(24):2925-34.

32. Pitts P, Goldberg R. Undermining patient values: the ASCO value in cancer care task force framework. J Commer Biotechnol. 2015;21(4):10-14.

33. Niven C, Hough N, Zhou A, Qin L, Alexander R. Assessment of clinical value in oncology: comparative analysis of value frameworks and HTAS. Value Health. 2016;19(7):A754 [Abstract PCN250].

34. Samson A, ed. The behavioral economics guide 2014. 1st ed. Available at: https://www.behavioraleconomics.com/BEGuide2014.pdf. Accessed April 10, 2017.

35. Robinson J. Economic Philosophy. New Brunswick, NJ, and London: ldineTransaction; 1962.

36. Porter ME. What is value in health care? N Engl J Med. 2010;363(26): 2477-81.

37. Neumann P, Sanders G, Russell L, Siegel J, Ganiats T. eds. CostEffectiveness in Health and Medicine. 2nd ed. New York: Oxford University Press; 2017.

38. Schnipper L. ASCO Value Framework: responses \& revisions. PharmacoEcon Outcomes News. 2016;755:1-18.

39. Weinstein M, Stason W. Foundations of cost-effectiveness analysis for health and medical practices. N Engl J Med. 1977;296(13):716-21.

40. Sheridan S, Pignone M, Mulrow C. Framingham-based tools to calculate the global risk of coronary heart disease: a systematic review of tools for clinicians. J Gen Intern Med. 2003;18(12):1039-52.
41. Gigerenzer G, Wegwarth O, Feufel MA. Misleading communication of risk. BMJ. 2010;341(7777):791-92.

42. Blinman P, King M, Norman R, Viney R, Stockler MR. Preferences for cancer treatments: an overview of methods and applications in oncology. Ann Oncol. 2012;23(5):1104-10.

43. Schwartz LM, Woloshin S, Welch HG. Risk communication in clinical practice: putting cancer in context. J Natl Cancer Inst Monogr. 1999;25(1):124-33.

44. Nace GS. The risk of risk: explaining difficult concepts to patients. March 18, 2009. Available at: http://www.onclive.com/publications/oncology-live/2009/mar2009/on_risk_of_risk?p=1. Accessed April 10, 2017.

45. Case LD, Kimmick G, Paskett ED, Lohman K, Tucker R. Interpreting measures of treatment effect in cancer clinical trials. Oncologist. 2002;7(3):181-87.

46. Zhong M, Hess K. Mean survival time from right censored data. Working Paper 66. Cobra Preprint Series. 2009. Available at: http://citeseerx. ist.psu.edu/viewdoc/download?doi=10.1.1.175.7502\&rep=repl\&type=pdf. Accessed April 10, 2017.

47. Lakdawalla D, Romley J, Sanchez Y, Maclean R, Penrod J, Philipson T. How cancer patients value hope and the implications for cost-effectiveness assessments of high-cost cancer therapies. Health Aff (Millwood). 2012;31(4):676-82.

48. Kim SH, Jo MW, Kim HJ, Ahn JH. Mapping EORTC QLQ-C30 onto EQ-5D for the assessment of cancer patients. Health Qual Life Outcomes. 2012;10:151.

49. Group TE. EuroQol-a new facility for the measurement of health-related quality of life. Health Policy. 1990;16(3):199-208.

50. Stolk EA, Oppe M, Scalone L, Krabbe PFM. Discrete choice modeling for the quantification of health states: the case of the EQ-5D. Value Health. 2010;13(8):1005-13.

51. Hofstatter EW. Understanding patient perspectives on communication about the cost of cancer care: a review of the literature. J Oncol Pract. 2010;6(4):188-92.

52. Silcocks P, Jenner D, Reza R. Life expectancy as a summary of mortality in a population: statistical considerations and suitability for use by health authorities. J Epidemiol Community Health. 2001;55(1):38-43.

53. Harris S, Brown J, Lopez J, Yap T. Immuno-oncology combinations: raising the tail of the survival curve. Cancer Biol Med. 2016;13(2):171.

54. Majer I, Gueron B, Kotapati S, Van Hout B. Extrapolating survival in a heterogeneous patient population with metastatic melanoma; a case study of integrating statistical and clinical consideration. Value Health. 2013;16(7):A594 [Abstract PRN107].

55. Latimer N. Estimating survival benefits in the presence of non-proportional and complex hazard function. Presented at: FDA-AARC ImmunoOncology Drug Development Workshop; Washington, DC; October 14, 2016. Available at: http://www.aacr.org/AdvocacyPolicy/GovernmentAffairs/ Documents/I-O\%20Day2\%20SlideDeck-safe.pdf. Accessed April 10, 2017. 